\title{
Targeting Policies for Multidimensional Poverty and Social Fragility Relief Among Migrants in Italy, Using F-FOD Analysis
}

\author{
Stefania M. L. Rimoldi ${ }^{1}$ (D) - Alberto Arcagni ${ }^{2} \cdot$ Marco Fattore $^{1}$. \\ Elisa Barbiano di Belgiojoso ${ }^{1}$
}

Accepted: 28 August 2020 / Published online: 10 September 2020

(c) The Author(s) 2020

\begin{abstract}
In this paper, we apply the novel Fuzzy First-Order Dominance (F-FOD) methodology to rank migrant subpopulations in Lombardy (Italy), in terms of multidimensional poverty and social fragility, for the year 2014, with the purpose to possibly provide useful support to policy-makers, in targeting relief interventions from poverty and discomfort. The F-FOD methodology allows for the direct comparison of different distributions of poverty and fragility, assessed by means of suitable ordinal multi-indicator systems, so extending to this more complex setting, the usual univariate first-order dominance criterion. It also provides complimentary "incomparability" scores, to assess to what extent the final rankings are reliable or instead forcing. It turns out that the levels of poverty and fragility of migrant subpopulations are quite different and, in particular, that the time since migrations has a key impact, on the identification of most critical cases, which typically involve recently migrated people. Evidence also emerges that the temporal poverty/fragility trajectories of migrants, distinguished by country of origin, follow different paths, suggesting how policy interventions must be properly, and differently, tuned to be effective.
\end{abstract}

Keywords Multidimensional poverty $\cdot$ F-FOD $\cdot$ Partially ordered sets $\cdot$ Ranking

Stefania M. L. Rimoldi

stefania.rimoldi@unimib.it

Alberto Arcagni

alberto.arcagni@unimib.it; alberto.arcagni@uniroma1.it

Marco Fattore

marco.fattore@unimib.it

Elisa Barbiano di Belgiojoso

elisa.barbiano@unimib.it

1 Department of Statistics and Quantitative Methods, University of Milano-Bicocca, Milan, Italy

2 Department of MEMOTEF, Sapienza University of Rome, Rome, Italy 


\section{Introduction}

In a recent paper by Arcagni et al. (2019), multidimensional poverty and social fragility of migrants' families in Lombardy (Italy) have been thoroughly explored, revealing a quite complex pattern in the levels and shapes of their social conditions. By using concepts from partial order theory, the study provides realistic estimates of poverty diffusion and sheds light on the social differences between and within migrants' groups, indirectly implying that no poverty relief policy can be effective, without accounting for the nuances of such inhomogeneous scenario. Drawing upon the same datasets, in the present paper we take a step further towards policy targeting and propose a new statistical procedure for ranking migrants' subpopulations, with the aim of providing policy-makers with actionable criteria supporting the definition of poverty relief interventions. To this goal, the critical issue is how to "condense" information on poverty and fragility into the respective rankings, still reflecting the complexity of these social traits and their nuanced patterns among migrants' groups. Indeed, any ranking built out of multidimensional indicator systems is essentially a dimensionality reduction process, which unavoidably loses information, in favour of simplicity and actionability. While some information loss must be accepted, the ranking method should nevertheless be designed in such a way to preserve, as much as possible, that part of information considered as more valuable. This leads to the use of partially ordered set theory, as the reference formal framework of our work, and to the adoption of so-called Fuzzy FirstOrder Dominance (F-FOD) analysis, as the cornerstone of our ranking procedure. We differ to a later section the description of such a statistical tool; here it suffices to say that F-FOD allows for multidimensional statistical distributions defined on partially ordered sets to be compared, in terms of relative dominance, without preliminarily "collapsing" them into some kind of synthetic indicators. In its essence, F-FOD performs a "synthesis of multidimensional comparisons between distributions", rather than performing a "comparison of synthesized multidimensional distributions", as one would do by using more classical aggregative procedures, like the much-revered Counting Approach of Alkire and Foster (2011a, b), or even the non-aggregative posetic approach to poverty evaluation, employed in Arcagni et al. (2019). This way, the dimensionality reduction step is "postponed" to the end the statistical process, making F-FOD inherently more "information and complexity preserving" than procedures passing through the evaluation of poverty or fragility at individual level. In this respect, the F-FOD procedure extends the classical univariate stochastic first-order dominance criterion, to the multidimensional ordinal setting, typical of social evaluation studies, and meets the need for more suitable poverty measurement tools; in particular, it helps overcoming the classical approaches based on monetary poverty lines, in particular when focusing on foreigners (Arcagni et al. 2019; di Belgiojoso et al. 2009; Busetta 2016; Lemmi et al. 2013).

The motivation of the present study is not only methodological, however; the paper does aim also at providing new insights on migrants' poverty and fragility, given the relevance of the migration phenomenon in the Mediterranean area and its impact on Italian society, and in Lombardy in particular. Reducing poverty is indeed the first goal of the UN 2030 Agenda for Sustainable Development, adopted by all United Nations Member States in 2015. According to it, countries recognize that ending poverty and other forms of deprivation is a key factor to promote peace and prosperity for people and the planet, now and into the future since, as stated by Pradhan et al. (2017, p. 1172) "SDG 1 (No poverty) has synergetic relationship with most of the other goals" (e.g. improvement of global health and wellbeing). Additionally, as many scholars acknowledge, poverty among migrants is generally more acute and persistent than among the host population (Bárcena-Martìn 
and Pérez-Moreno 2016; Berti et al. 2014; Kazemipur and Halli 2001; Lelkes 2007; de Bustillo and Anton 2011; Obućina 2014; Pastor 2014) and so reducing migrants' poverty is a key step to reduce the overall level of poverty in the whole society, particularly in countries with large immigration flows, like Italy. This motivates the focus of the present paper, which is specifically devoted to the ranking of migrants' families, for policy targeting. More concretely, we cluster migrant families by country of origin and years since migration, two features that have been observed to be linked to migrants' social conditions (Arcagni et al. 2019), and compare the corresponding frequency distributions on a multidimensional set of poverty and fragility indicators, by using the aforementioned F-FOD procedure. From the resulting set of pairwise comparisons, a final ranking is eventually obtained, identifying the most critical subpopulations, to be considered by policy-makers. Besides, a complementary measure of the degree of "incomparability" among clusters is provided, to assess the reliability of the rankings and to preserve a feeling of the intrinsic and irreducible complexity of migrant's social conditions.

The paper is structured as follows: Sect. 2 provides some background about research on poverty; Sect. 3 describes the input data used in the subsequent analysis. Section 4 outlines the F-FOD procedure; Sect. 5 illustrates the results and Sect. 6 draws the conclusions.

\section{Background Research on Migrants' Poverty}

Measuring poverty among migrants' families is the first step in the process of contrasting poverty in the Italian society, where migration has introduced an additional feature of complexity, particularly in the issue of deprivation (Istat 2018). Some specific traits of current poverty in Italy come indeed from the social transformation of the Italian population over the last decades. As well known, Italy has been experiencing large flows of migrants from poor countries since the end of the Nineties. Over time, these migrants settled in Italy forming a population that, at the end of 2018, amounted to 5.3 million residents (Istat 2019). Although, in some measure, the integration process has been achieved for a part of foreigners, there is still a large share of them living in poor conditions. Currently, the proportion of families living below the national (relative) poverty line among the families entirely composed of foreigners is $34.5 \%$ in 2017 (23.9\% among mixed families) vs. 10.5\% among Italian families (Istat 2018). Moreover, migrants are the poorest among the poor and a large number of studies in various contexts, confirm that poverty among migrants tends to be more marked and persistent than among natives in various countries (BárcenaMartìn and Pérez-Moreno 2016; Kazemipur and Halli 2001; Lelkes 2007; de Bustillo and Anton 2011; Obućina 2014; Pastor 2014) and in Italy as well (Berti et al. 2014). Various explanations have been attempted, to better account for the link between migration and poverty. They usually refer to migrants' legal status, to their educational attainments and poor host language proficiency, to relatively lower job skills, to age and family status and the length of stay (Hansen and Wahlberg 2009; Sullivan and Ziegert 2008). Indeed, in Arcagni et al. (2019), it is underlined how capturing migrants' poverty is a difficult task from many points of view. Migrants are an unstable population, due to its frequent crossborder or "in transit" nature; moreover, methodological issues arise due to problems in data collection and to the specificity of migrants' social conditions, which require measurement methodologies to be properly tuned (Aaberge et al. 1999; di Belgiojoso et al. 2009; Berti et al. 2014; Galloway and Aaberge 2005; Koutsampelas 2015; Lemmi et al. 2013; Rimoldi and di Belgiojoso 2016). Therefore, various attempts have been carried out in research to 
overcome the traditional approach, based on the comparison of family income to a predetermined threshold, or poverty line, which proves problematic and not so effective in the case of migrants (Arcagni et al. 2019; di Belgiojoso and Rimoldi 2005; di Belgiojoso et al. 2009; Busetta 2016; Lemmi et al. 2013). A common thread among most of these proposals is the acknowledgement that poverty is a complex multidimensional trait, which cannot be assessed just in monetary terms.

This paper focuses on two main suffering domains, namely poverty and social fragility; the first refers to actual deprivation status and the second, to the exposure to critical conditions that might evolve into poverty, or worsen already deprived situations (Arcagni et al. 2019). To capture the complexity of deprivation (Koutsampelas 2015), beyond purely monetary aspects, poverty status is assessed by adding to income the dimensions of living arrangements, economic aid, and medical treatment renunciation. As for living arrangements, an extensive literature considers homeownership as a factor of economic success and a marker of well-being (Bárcena-Martìn and Pérez-Moreno 2016; Constant et al. 2009; Davidov and Weick 2011; Gobillon and Solignac 2015; Myers and Lee 1998). For migrants, in particular, homeownership is an important step toward a definitive settlement in the host country, reflecting the will and the commitment to stay (Constant et al. 2009; Davidov and Weick 2011; Rimoldi and di Belgiojoso 2016); on the contrary, precarious accommodation and shared dwelling, often overcrowded, correspond to certain poverty status (Diana and Strozza 2014; Robinson et al. 2007). Recourse to economic aid is a frequent practice in conditions of poverty: we assume that recourse to institutional aid corresponds to nontransitory poverty, while recourse to one's own kinship or friendship network support corresponds to transitory poverty, based on research evidence showing how recourse to institutional aid decreases as the length of stay increases (Hansen and Lofstrom 2003; Lie 2002). ${ }^{1}$ Unmet medical needs are strictly linked to poverty (Busetta 2016; Fernades and Pereira 2009; Koolman 2007), moreover, empirical evidence shows that migrants in Italy experiment knowledge barriers to health care such as scarce information about national regulations (Busetta 2016; Giannoni 2010). Unsatisfied education needs and socialization needs, although important factors in explaining migrants' poverty and integration (Kazemipur and Halli 2001), could not be included because not available in the survey.

Social fragility here is intended as the vulnerability of families deriving from individual unstable working conditions together with work-family models, which describe the relationship between family size and the number of its members in employment (Fellini and Migliavacca 2010). Therefore, based on the fact that increasingly precarious work conditions directly affect consumption, housing and health (Obućina 2014; Pemberton et al. 2014), we describe social fragility through the working dynamics (ranging from the condition of persistent unemployment to stable employment). To catch the family dimension, we introduced both a variable describing the effects of remittances on consumption and saving behaviour due to the presence of a family in the country of origin, and a variable accounting for the fragility of families with just a single income source, which are commonly considered as having a higher risk of poverty (Curatolo and Wolleb 2010). Finally, not having a residence permit represents, for an immigrant and his family, a serious element of precariousness, not allowing access to any opportunities offered by social policies at the various territorial levels to support the integration.

\footnotetext{
1 This hypothesis is valid when dealing with the stable resident foreign population, as it is the case of the sample used in this paper; otherwise, migrants in the first period after immigration have difficulties to access institutional opportunities and are forced to lean on their social network.
} 
We address this issue by employing procedures based on the theory of partially ordered sets—as introduced by Fattore (2016) and Fattore and Arcagni (2018)—which are properly designed to work fuzzy measures out of ordinal multi-indicator systems. Results coming from Arcagni et al. (2019) support such "posetic" approach, showing that deprivation among migrant families has a highly fuzzy and nuanced trait, with a limited quota of completely or almost completely poor units and a much larger part of population sharing, to different extents, deprivation facets. In fact, the overall picture of migrants' poverty hides specific patterns of poverty by country (or geographical area) of origin: Sub-Saharan migrants face the hardest condition, while Chinese and Filipinos have the best scores both for poverty and fragility. In addition, country of origin intertwines with years since migration in explaining poverty and fragility performances (for example, East Europeans migrants, although with a long mean duration of presence-usually negatively correlated to poverty -, suffer from partial deprivation, due to their specific migration model, i.e. being mostly alone with family left behind and often one-income family).

The posetic approach adopted in Arcagni et al. (2019) aimed primarily at assessing the poverty and fragility degrees of individuals, comparing them to some multidimensional benchmarks, in a "threshold-like" spirit. From individual degrees, poverty and fragility patterns were outlined and synthetic indicators were computed, to compare migrants' subgroups. Here, the aim is somehow different, in that we want to get rankings of migrants' subpopulations, without going through the computation of any individual scores, but directly quantifying the degree of dominance among subpopulations, when these are multidimensionally compared against the set of poverty and fragility attributes. As mentioned in the Introduction, the F-FOD procedure provides such a quantification and finally leads to poverty and fragility rankings.

\section{Data}

Data on the socio-economic conditions of migrants and migrants' families in Lombardy come from the 2014 ORIM $^{2}$ Survey, held as part of the regional monitoring activity on foreign population. ORIM surveys are conducted each year on a sample of migrants aged 15 and over and coming from "less developed countries" and also from Central and Eastern Europe. Interviewees are randomly selected according to the Centre Sampling Method (Baio et al. 2011), which ensures representativeness at both the regional level and provincial level (Blangiardo 2008). The method is based on a two-stage design: municipalities are the first level units selected according to their share of migrants and their demographic representativeness at the regional level, migrants (second level units) are then randomly selected among those who frequent a set of aggregation centres previously identified in each of the first level units. The underlying hypothesis of this method is that in everyday life migrants frequent some services or places, defined "aggregation centres" (such as institutions, place of worship or entertainment, training centres, care centres, meeting points, ethnic shops, telephone centres...) and the profile of centers frequented by each migrant can be used a posteriori to estimate the weights to correct the initial probability of inclusion in the sample. The weights are inversely related to the inclusion probability, as this guarantees the representativeness of the sample and corrects the initial bias (Baio et al.

\footnotetext{
${ }^{2}$ ORIM stands for "Osservatorio regionale per l'integrazione e la multietnicità?" ("Regional observatory on integration and multiethnicity").
} 
Table 1 Population by country (or geographical area) of origin and years since migration. Source: own elaborations on ORIM data

\begin{tabular}{|c|c|c|c|c|c|c|}
\hline \multirow[t]{2}{*}{ Country/geographical area of origin } & \multicolumn{5}{|c|}{ Years since migration } & \multirow[t]{2}{*}{ Total } \\
\hline & $<2$ & $3-5$ & $6-9$ & $10-14$ & $15+$ & \\
\hline Albania (AL) & 6 & 10 & 25 & 94 & 102 & 237 \\
\hline China $(\mathrm{CHN})$ & 13 & 35 & 26 & 53 & 66 & 193 \\
\hline India, Pakistan, Sri Lanka, Bangladesh (IPSB) & 31 & 56 & 94 & 169 & 147 & 497 \\
\hline Latin American (LA) & 17 & 29 & 74 & 163 & 141 & 424 \\
\hline North Africa (NA) & 29 & 60 & 142 & 246 & 525 & 1002 \\
\hline Philippines (PH) & 0 & 7 & 11 & 12 & 39 & 69 \\
\hline Romania (RO) & 15 & 25 & 42 & 95 & 49 & 226 \\
\hline Sub-Saharan Africa (SSA) & 72 & 97 & 141 & 186 & 218 & 714 \\
\hline Ukraine and Moldova (UM) & 11 & 48 & 62 & 100 & 26 & 247 \\
\hline Total & 194 & 367 & 617 & 1118 & 1313 & 3609 \\
\hline
\end{tabular}

2011; Sanguilinda et al. 2017). This way, the sample is representative also for specific subgroups, such as illegal migrants or ethnic groups. The data comprise a set of socio-demographic variables (family composition, migratory characteristics, economic information...) and a yearly thematic in-depth section. The 2014 survey involved 4000 subjects living, legally or illegally, in Lombardy, including migrants in a mixed union, and the in-depth section was specifically devoted to migrants' economic conditions.

As highlighted in Arcagni et al. (2019), migrants' poverty and fragility are mainly shaped by country (or geographical area) of origin and years since migration. In the present paper, we thus investigate on migrants' group poverty and fragility along these two dimensions. Overall, we selected 3609 subjects. ${ }^{3}$ Table 1 shows the final composition of the population object of study.

In the following, we briefly recall the variables used to describe the two domains of poverty and social fragility for migrant families, and the complimentary covariates used to break down the set into sub-groups.

\subsection{Poverty and Social Fragility Attributes}

Poverty status is based on four attributes:

1. Living arrangement, coded on a 5-degrees scale: $1=$ "Living in encampment, shacks, squatting"; 2 = "Tenant with other migrants (not relatives)"; $3=$ "Living at the workplace"; 4 = "Tenant alone or with family"; 5 = "Homeowner".

2. Economic aid, coded on a 3-degrees scale: $1=$ "Institutional aid"; 2 = "Kinship's aid"; $3=$ "No aid".

3. Medical treatment renunciation, coded on a 3-degrees scale: $1=$ "Renunciation to medical treatment or resort to remedies"; $2=$ "Return to the country of origin for medical treatment"; 3 = "No renunciation".

\footnotetext{
3341 subjects have been excluded, due to the too small size of their nationality group and 47 subjects have been excluded because years since migration were not available.
} 
4. Equivalent monthly net family income (in euros), coded on a 4-degrees scale, according to the quartile the equivalent family income (I) belongs to: $1=\mathrm{I} \leq 845$; $2=846 \leq \mathrm{I} \leq 1206 ; 3=1207 \leq \mathrm{I} \leq 1639 ; 4=\mathrm{I}>1639$. The family income is adjusted according to the "migrants equivalence scale", introduced and estimated by Rimoldi and di Belgiojoso on the basis of the Engel's law (Rimoldi and di Belgiojoso 2016).

Migrants' social fragility is described and assessed based on the following four ordinal attributes:

1. Working dynamics, coded on a 6-degrees scale: $1=$ "Persistent unemployment"; $2=$ "Run into unemployment" (employed one year before the survey, but unemployed at the time of the survey); $3=$ "Run into instability or persistent precariousness" (stably employed one year before the survey, but precariously employed at the survey or precariously employed at the survey and one year before); $4=$ "Non-active status" (housewife, student and retired); $5=$ "Improving condition" (unemployed one year before the survey, but employed at the time of the survey); $6=$ "Persistent and stable employment" (employed one year before the survey and employed at the time of the survey).

2. Legal status, ${ }^{4}$ coded on a 2 -degrees scale: $1=$ "Illegal"; $2=$ "Legal".

3. Dependent family in country of origin, coded on a 2-degrees scale: $1=$ "Yes"; $2=$ "No".

4. One-income family, coded on a 2-degrees scale $1=$ "Yes"; 2 = "No".

Among the complimentary variables, we focused on the following in order to target the groups:

1. Country or geographical area of origin ("Sub Saharan Africa (SSA)"; "NorthAfrica (NA)"; "Albania (AL)"; "Romania (RO)"; "Ukraine and Moldova (UM)"; "Latin America (LA)"; "Philippines (PH)"; "China (CHN)"; "India, Pakistan, Sri Lanka and Bangladesh (IPSB)").

2. Years since migration of the forerunner (in years, quantitative). This variable appears to be usually negatively correlated with poverty since, as migrants stay longer in the host country, their poverty level tends to decrease. The variable is coded in the following categories: "0-2", "3-5", "6-9", "10-14" and "15 or more". For the crossed analysis with country of origin, we used the following categories " $0-5$ ", "6-9", "10 or more", so as to reduce the number of subpopulations to consider, without oversimplifying the analysis.

\section{Partially Ordered Set and the F-FOD Procedure}

In the following, we provide some basic definitions and concepts of partially ordered set (poset) theory and outline the F-FOD procedure, in an intuitive manner. Formal details can be found in cited references.

We motivate the use of partially ordered set by means of a simple example. Consider the variables used to describe migrants' social fragility ${ }^{5}$; the list of scores describing each

\footnotetext{
${ }^{4}$ Legal status refers to the sojourn condition of migrants. More specifically, "legal" migrants are migrants with a sojourn permit, Italian or European citizens while "illegal" migrants are those migrants without permit (undocumented).

${ }^{5}$ The discussion for poverty status is completely analogous.
} 
individual fragility pattern is here called a (fragility) profile. Although the input variables are ordinal, profiles are multidimensional entities that in general cannot be ordered, due to the existence of possible conflicting scores between them. To clarify this point, consider three migrants A, B and C, with the following fragility profiles: A-6211 (persistent and stable employment, legal status, with a dependent family in the country of origin and one-income family), B-5222 (improving condition, legal status, without a dependent family in the country and with more than one-income in the family) and C-2122 (run into unemployment, illegal status, without a dependent family in the country and with more than one-income in the family). The profile of migrant $\mathrm{C}$ is more fragile than that of $\mathrm{B}$, due to unemployment and illegal status; on the contrary, the profiles of migrants $\mathrm{A}$ and $\mathrm{C}$ are not comparable (i.e. they are incomparable). In fact, while profile $\mathrm{A}$ is more fragile than $\mathrm{C}$ on one attribute, it is less fragile on another, so that the two profiles cannot be ordered. As a result, the set of all the possible profiles cannot be completely ordered in terms of fragility and is thus named a partially ordered set (or a poset, for short) i.e. a set where the possibility of comparing elements is only partial. Partially ordered sets arise naturally when multidimensional systems of ordinal attributes are to be dealt with and provide the formal setting for the analysis carried on in the next section. For this reason, here we provide some definitions and basic tools from partial order theory, so to make the present paper self-contained and clarify subsequent developments.

A (finite) poset $P=(X, \leq)$ is a set $X$ of finite cardinality $k$, equipped with a partial order relation $\leq$, i.e. with a reflexive, antisymmetric and transitive binary relation (Davey and Priestley 2002; Neggers and Kim 1998; Schröder 2003). An easy way to specify the structure of a poset, is by stating the dominance between pairs of elements of the underlying set $X$. This is more effectively done by introducing so-called incidence matrix $\mathrm{Z}$, which is a $k x$ $k$ matrix defined by

$$
Z_{i j}=\left\{\begin{array}{l}
1 \text { if } x_{i} \leq x_{j} \text { in poset } P \\
0 \text { otherwise }
\end{array}\right.
$$

for $x_{i}, x_{j} \in X$.

We already introduced in the example the concept of incomparability between two profiles. In general, two elements $x_{i}, x_{j} \in X$ are incomparable if neither $x_{i} \leq x_{j}$ and $x_{j} \leq x_{i}$, i.e. $Z_{i j}=Z_{j i}=0$.

Posets can be graphically represented by so-called Hasse diagrams, a kind of directed acyclic graphs which help visualizing the partial order structure (usually, when the number of elements of $X$ is not too large). For exemplification purposes, the Hasse diagram of the partial order built upon the set of all possible fragility profiles is represented in Fig. 1.

In the Hasse diagram, each node corresponds to a poset element; if $x_{i}<x_{j}$ in the input poset, then node corresponding to $x_{j}$ is placed higher than the node corresponding to $x_{i}$ and an edge is drawn between them, if and only if there is no other $x_{h}$ such that $x_{i}<x_{h}<x_{j}$. Downward paths in the Hasse diagram reconstruct the dominances between poset elements; two nodes not connected by any downward path are thus incomparable.

Simple as they may seem, posets may comprise a great deal of information on input data, useful to perform evaluations on multi-indicator systems or to build rankings of statistical units and of sub-groups of the population of interest. The formal development of the procedures for the statistical treatment of partially ordered structures is however not entirely trivial and can be found in cited references. Here we simply outline, by means of a simple example, the F-FOD procedure, later employed to rank target subpopulations in terms of poverty or fragility. 


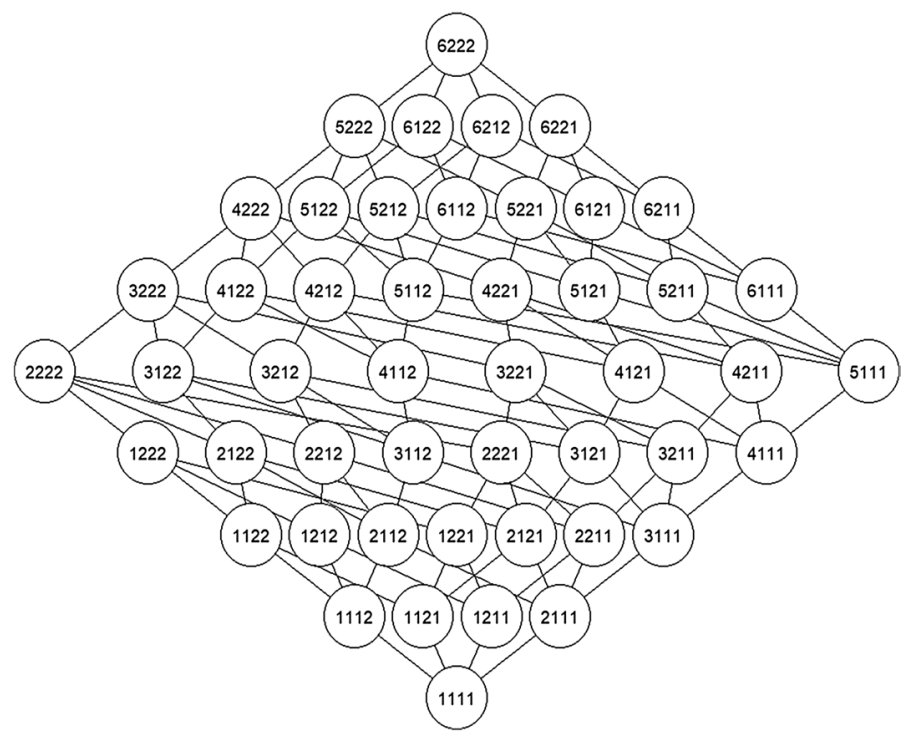

Fig. 1 Hasse diagram of the social fragility poset
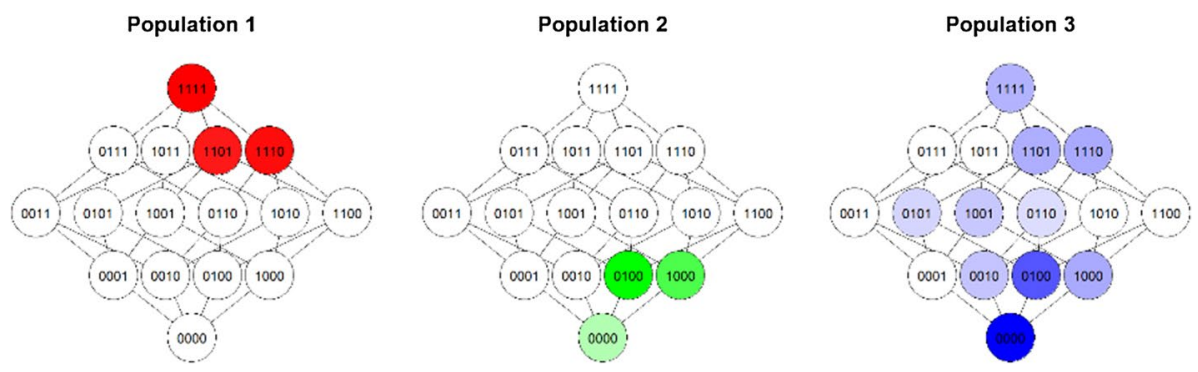

Fig. 2 Statistical distributions on the poset built upon four binary attributes. Color intensities are proportional to frequencies. (Color figure online)

Consider an indicator system comprising four binary attributes, evaluated on three different populations. Different units in each population may share the same scores on the four attributes, so that to each binary profile a relative frequency is associated. Suppose that the statistical distributions associated to the three populations can be represented as in Fig. 2, where the more intense the color, the higher the corresponding frequency.

Intuitively, the first distribution is better (i.e. higher) than the other two and the third is better than the second. However, it is not clear how to make this feeling objective, given that the domain of such distributions is only partially ordered and not all profiles are comparable. The solution to this issue is provided by the Fuzzy First-Order Dominance procedure (Fattore and Arcagni 2019), which is an extension, to the partially ordered case, of the first-order dominance criterion, used to compare distributions defined over the real axis (or over subsets of it). F-FOD combines poset theory and fuzzy set theory, with the approach to first-order dominance with multiple discrete indicators, proposed by Arndt 
et al. (2012), overcoming the main limitations of the latter and providing a natural way to quantify dominance degrees between statistical distributions over posets.

With reference to the above example, the basic idea behind the F-FOD can be sketched as follows.

1. Consider the set of 16 binary profiles of the poset underlying the distributions of Fig. 2 and form all of the 16 ! so-called linear orderings corresponding to their permutations. Such orderings can be subdivided into two classes: the class of linear orderings preserving the comparabilities of the input poset (i.e. such that $x_{i}<x_{j}$ in the poset implies $x_{i}<x_{j}$ in the linear ordering) and the set of linear orderings that do not (i.e. such that there is at least one comparability $x_{i}<x_{j}$ in the poset such that $x_{j}<x_{i}$ in the linear ordering). The linear orderings belonging to the first class are called the linear extensions of the poset; they are all the possible orderings of poset elements compatible with the constraint imposed by the comparability structure of the original partial order relation.

2. A fundamental theorem of poset theory states that any finite poset is equivalent to the set of its linear extensions, so that the poset can be uniquely reconstructed from such a set (Schröder 2003). As a consequence, the quantification of the relative dominance of two distributions over the input poset can be addressed by quantifying their relative dominance on the corresponding linear extensions.

3. Interestingly, a linear extension can be considered as a univariate ordinal variable, so in it one can quantify the relative degree of first-order dominance of two distributions in a rather straightforward way, i.e. by computing the probability that a unit randomly sampled from the first distribution is dominated, in the considered linear extension, by a unit randomly sampled from the second.

4. Such "elementary" dominance degrees can be computed for each linear extension and finally averaged to get the final dominance score between the two distributions.

5. Repeating steps 3 and 4 for each distribution pair, the F-FOD procedure eventually provides a matrix $\Delta$, whose entry $\Delta_{i j}$ is the degree of dominance of distribution $j$ over distribution $i$.

6. Once matrix $\Delta$ is available, one can compute a degree of dominance of distribution $i$ over the others by averaging its dominance degree over each other distribution, i.e. by computing the following index:

$$
d o m_{j}=\frac{1}{h-1}\left(\sum_{i=1}^{h} \Delta_{i j}-1\right) .
$$

where $h$ is the number of compared distributions.

Remark In practice, the above procedure is implemented in a slightly simplified manner, i.e. by considering not all of the linear extensions of the poset, but the subset of so-called lexicographic linear extensions (Fattore and Arcagni 2019). Suppose you order poset profiles based on their score on the first variable and, in case of ties, on their score on the second variable and so on, in an "alphabetic" fashion; the final linear order can be proved to be a linear extension of the input poset, called lexicographic (Fattore and Arcagni 2019). Permuting the order of the variables in the above process, one gets a set of $k$ ! (where $k$ is the number of variables) lexicographic linear extensions, which can be proved to uniquely determine the input poset, as the set of all of linear extensions does. In general, the number of lexicographic linear extensions is much less than that of all linear extensions and so 
Table $2 \Delta$-matrix and dominance scores for the toy example

\begin{tabular}{llll}
\hline & Pop. 1 & Pop. 2 & Pop. 3 \\
\hline Pop. 1 & 1.000 & 0.000 & 0.187 \\
Pop. 2 & 1.000 & 1.000 & 0.670 \\
Pop. 3 & 0.899 & 0.492 & 1.000 \\
Dominance & 0.950 & 0.246 & 0.428 \\
\hline
\end{tabular}

\begin{tabular}{llll}
\hline & Pop. 1 & Pop. 2 & Pop. 3 \\
\hline Pop. 1 & 0.000 & 0.000 & 0.187 \\
Pop. 2 & 0.000 & 0.000 & 0.492 \\
Pop. 3 & 0.187 & 0.492 & 0.000 \\
Incomparability & 0.094 & 0.246 & 0.340 \\
\hline
\end{tabular}

Table 3 I-matrix and incomparability scores for the toy example

emplying just them, heavily reduces the computational burden of the procedure and allows F-FOD to be applied to larger multi-indicator systems, than that used in the above toy example. The procedure is implemented in the $\mathrm{R}$ package parsec (Arcagni 2017) available on the R Comprehensive Archive Network (R Core Team 2019).

Table 2 shows the $\Delta$-matrix for the toy example and the corresponding average dominance scores. From it one can directly rank the distributions. Notice that the average dominance scores provide metric information, which enriches the ranking, by providing the "dominance distance" between pairs of distributions.

As mentioned in the Introduction, any ranking extraction implies some unavoidable information loss, since incomparable multidimensional inputs are made comparable and forcedly placed on a single axis. The F-FOD procedure is no exception, but interestingly it provides a way to complement the average dominance scores with information on the degree of incomparability of a distribution, with respect to the others; this way, one can assess to what extent a distribution is forced into the ranking. To compute such incomparability scores, the dominance matrix $\Delta$ is turned into the incomparability matrix I, which is symmetric and whose entries are defined by $\mathrm{I}_{i j}=\min \left(\Delta_{i j}, \Delta_{j i}\right)$ (so, the higher the degree of dominance, the lower the degree of incomparability between two distributions), and then the following incomparability score is computed for each distribution:

$$
i n c_{j}=\frac{1}{h-1}\left(\sum_{i=1}^{h} \mathrm{I}_{i j}-1\right) .
$$

Table 3 reports the incomparability matrix, for the three populations example.

We conclude this methodological section with a final comment. The F-FOD may at first seem an aggregative procedure (like the construction of composite indicators), in that it computes the final dominance scores between two distributions, by aggregating "elementary" dominance scores. But here it is the key difference with respect to classical scoring procedures: the aggregation is not performed on the input variables, but on the linear extensions, which is a way to exploit the information comprised in the structure of the underlying poset. This is why, in the Introduction, we stressed that the F-FOD is more "information and complexity preserving" than other tools, since it exploits the deep structure of the input data. 


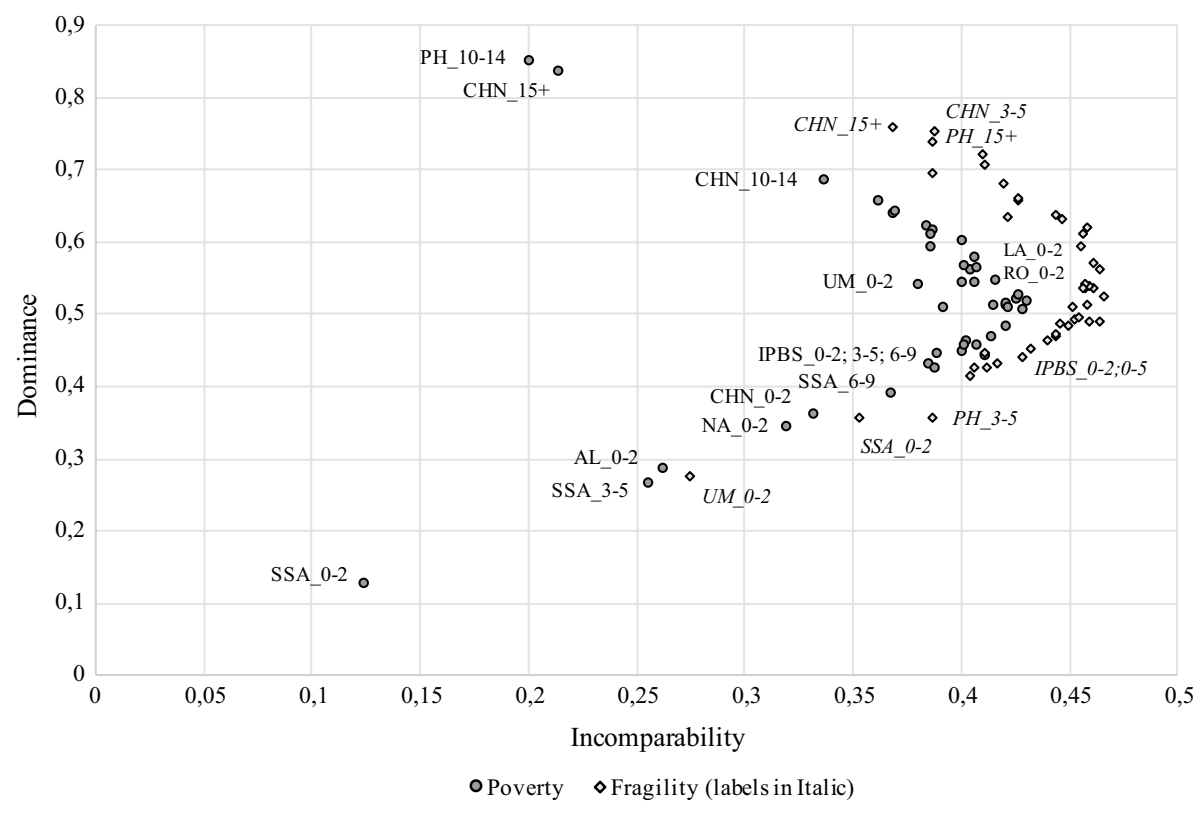

Fig. 3 Poverty and fragility scores (dominance and incomparability) by country of origin and length of stay in Italy

\section{Results}

We applied the F-FOD procedure to our data described for both poverty and social fragility. From Fig. 3 (detailed data can be found in the "Appendix 1" to this paper), it turns out that migrant groups can be indeed ordered by poverty and fragility dominance scores (the higher the scores, the lower the poverty and fragility levels), even if some of the subgroups are quite incomparable to the others, confirming the existence of quite complex patterns in migrants' social conditions. Indeed, some sub-populations in highly critical conditions neatly emerge from the data and have the lowest incomparability level (namely Sub-Saharan migrants).

Based on the reported poverty and fragility scores, the primary role of years since migration clearly emerges. Almost all the migrant groups most recently arrived ( $0-2$ years since migration) are on top of the rankings of both poverty and fragility (i.e. they have low dominance scores): as for poverty, except for Latin Americans, Ukrainians and Moldovan and Romanians (whose dominance score is higher), migrants with the lowest length of stay account for $4.2 \%$ of total population; as for fragility, disregarding Chinese, they account for $5.0 \%$ of population. Symmetrically, migrants with the longest duration of presence (10 years at least) generally occupy the most favorable position in poverty and fragility rankings; notice that they account for $67.4 \%$ of the total population.

Interestingly, poverty and fragility hit the groups in different ways, both by duration of the presence and by country. For instance, as long as years since migration increases (at least up to 10 years), Filipinos tend to reduce both their poverty and fragility while Chinese, while reducing poverty, tend to maintain their level of fragility, although very modest. It should be noticed, however, that the results pertaining to Filipinos can be affected by instability, since the small dimension of their sample (see Table 1). 
More in depth, from Fig. 3 it also emerges that Sub-Saharan Africans (SSA)-19.8\% of the total population-are not only the poorest, but they are also among the most fragile groups: they report the lowest scores of poverty dominance (that means highest poverty) even for a long duration of presence (up to 9 years) and the lowest scores of fragility dominance, although only for those more recently arrived (years since migration $<6$ ). The group "India-Pakistan-Sri Lanka-Bangladesh" (13.8\% of the population) also shows low dominance scores up to 9 years since migration on the poverty side, and up to 5 years since migration on the fragility side.

As for fragility, the duration of presence seems to be a less incisive protection factor for some groups like Ukrainians and Moldovans (6.8\% of the population), and it is almost uninfluential for Chinese (5.3\%), who are in favorable position whatever the duration of presence. Notice the role of the variable "Dependent family in country of origin" in fragility scores, which is especially important for Ukrainians and Moldovans. Chinese and Filipinos with long duration of presence (10 years at least) suffer from neither poverty nor fragility, although the most recently arrived Filipinos (3-5 years) report a high score for fragility.

Poverty and fragility rankings, however, must be considered in the light of the incomparability scores, that tell about the level of certainty of the ranking positions. Figure 3 illustrates the rankings skewed by the incomparability: points laying on the right side of the graph are more uncertain than the others (since they are to a larger extent incomparable with the other elements). Therefore, it is immediately apparent that fragility is more uncertain than poverty. Moreover, while uncertainty is low both at the top (i.e. for SSA_0-2, SSA_3-5, AL_0-2) and at the bottom (i.e. for PH_10-14, CI_15+) of the ranking of poverty (making these positions rather sure), it does not decrease along with the fragility score, so that fragility is almost certain only when it is high (i.e. for UM_02, SSA_02, PH_3-5).

It should be noticed that the incomparability scores measure to what degree a distribution is, on average, incomparable with the others; but since there are "many ways" to be incomparable, similar scores do not mean similar poverty/fragility distributions. Thus, subpopulations placed nearby on the incomparability axis of Fig. 3, need not be similar, in social terms.

Finally, it is of considerable interest to jointly examine the trajectories of poverty and fragility along with the duration of the presence. From Fig. 4 (detailed data can be found in the "Appendix 1" to this paper), we can derive some interesting tips (recall that low dominance scores mean high poverty/fragility levels, so that over the bisector groups are placed subpopulations for which the poverty level is higher than the fragility level). A general trend towards reduction over time of both poverty and fragility can be clearly noticed, even if along different trajectories, for different groups. The figure compares migrants who are at a different stage of their migration experience (length of stay) by area of origin with a cross-sectional approach. The trajectories do not describe the change in poverty and fragility among a cohort of migrants during their migration experience. Thus, the results should be read with caution because some context effects could bias the trends. However, this figure allows us to have an idea of the possible evolution along the migration experience. At the beginning of the migration experience, migrants suffer from different levels of poverty and fragility (e.g. for Sub-Saharans and North-Africans, poverty is much higher than fragility), but as time in migration passes, poverty and fragility tend to converge towards lower and more similar levels. Migrants from Ukraine and Moldova and from Philippines start their migration with more fragility than poverty, but over time their fragility transforms into poverty, although on lower levels. Filipinos start with some fragility, but they rapidly escape from it. Conversely, Albanians start their migration as relatively poor, but they then turn poverty into fragility during the first years of migration; after 10 years, their 


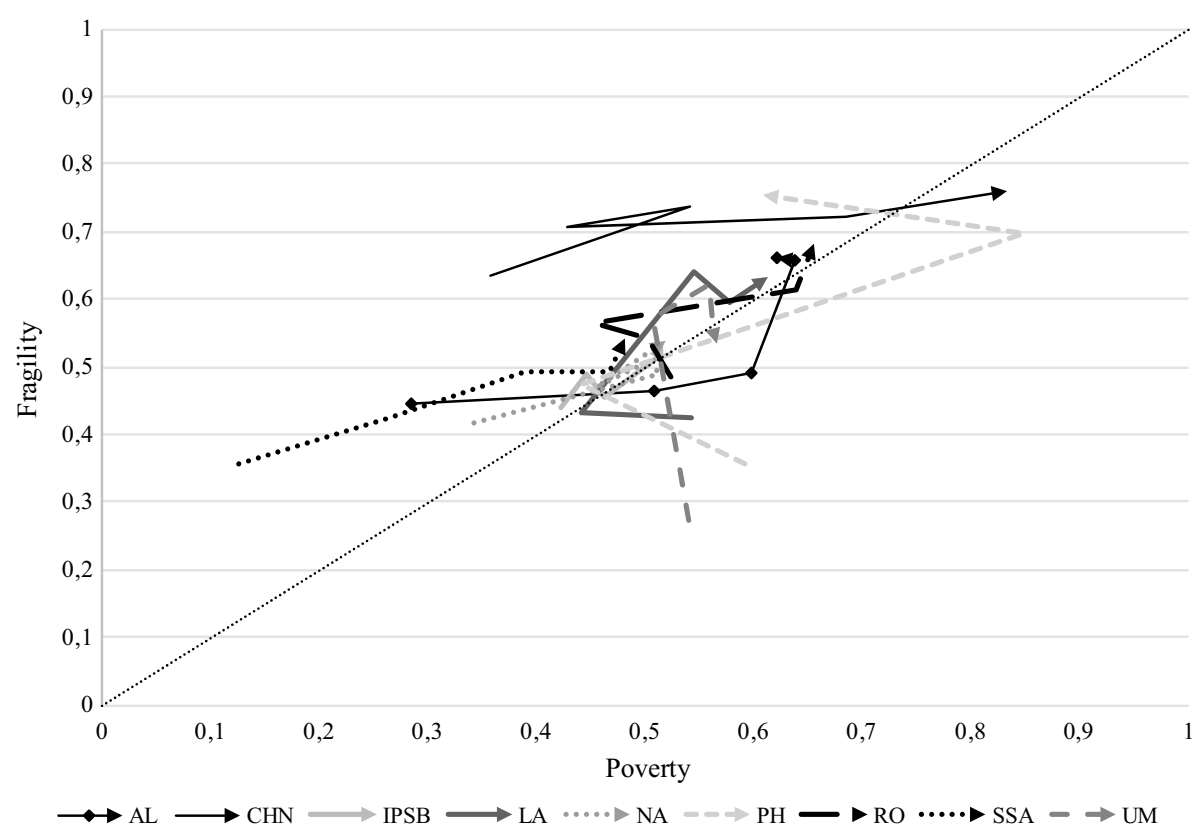

Fig. 4 Poverty and fragility scores comparison colored by geographical area/country of origin and arrows indicating the increasing years since migration

poverty level decreases. Chinese's trajectory moves quite horizontally after 5 years since migration, meaning they are almost untouched by fragility along their durable migration.

These results indicate that the most urgent condition refers to migrants from Sub-Saharan Africa especially those recently arrived. To improve their condition, policies should be activated (or if existing, improved) to provide them with support in many multiple directions: first, social policies could be allowed also to undocumented migrants (e.g. the case of children denied access to social services because their parents are irregular migrants); second, living arrangement could be improved by encouraging social housing; third, barriers to access to medical treatment could be removed by information campaign; finally, a stable income could derive from helping migrants' labour market integration by matching demand and supply. For example, the high level of fragility of recently arrived Ukrainians and Moldovans strongly depend on their occupational instability due to the fact that they usually work in the domestic sector without a contract, moreover they have a dependent family in their country of origin and their income is the sole family income. Policies aimed at increasing the regular recruitment of domestic workers could reduce their fragility.

\section{Conclusions}

In this paper, we have addressed the problem of ranking migrant subgroups in terms of poverty and fragility in a multidimensional ordinal setting, using novel statistical tools, based on poset theory. The aim of the paper is to possibly provide insights to policy-makers, in view 
of targeting poverty relief interventions, by resolving the differences among migrant clusters and identifying the most critical cases. Reducing poverty is unanimously recognized as a priority for all governments, and scholars agree in identifying migrants as the poorest among the poor; however, measuring poverty among migrants is still an open issue and this paper aims to provide a contribute in this respect. Considering the limited budget available for poverty contrasting, tools capable to target and focus on most problematic subpopulations are indeed desirable, for effective and efficient policy-making. In this perspective, the F-FOD procedure employed in this paper proves valuable, providing decision-makers with both rankings and scores, useful to quantifying the priorities and the impact of possible policies. The relevance of these features is confirmed also in the present paper, where it emerges the primary role of years since migration in ranking poverty and fragility: indeed, migrants most recently arrived (up to 5 years since migration, that is $15.5 \%$ of total population) suffer, with different intensity by country of origin, from both poverty and fragility. This suggests implementing policies to facilitate the initial settling of migrants, for example through housing policies (for poverty), or legal status policies (for fragility). The paper also identifies recently arrived Sub-Saharan and Albanian subpopulations as the most critical cases: the first stay in poverty also for longed duration of presence, up to 9 years, the second only when just arrived. These groups, which account for $4.8 \%$ of total migrants, are quite certainly the poorest, suggesting policy-makers to design policies tuned to these subpopulations' needs. As noted in background section, results from previous research (Arcagni et al. 2019) evidenced specific patterns of poverty by country of origin: country of origin here represents the variable which conveys all the dimensions (such as pre-emigration conditions, migratory paths, cultural dimensions, etc.) not specifically invoked to explain poverty in the host country; therefore, this paper aims to offer to policy makers a cross cut of migrants' poverty through this dimension, helping them to tune more conveniently their policy interventions.

On a more general ground, the paper shows how it is possible to develop effective statistical and measuring tools in a multidimensional ordinal setting and, in particular, how it is possible to build rankings in a sound way, providing a firm basis to the production of these kind of statistics, for policy-makers.

Funding Open access funding provided by Università degli Studi di Milano - Bicocca within the CRUICARE Agreement.

Open Access This article is licensed under a Creative Commons Attribution 4.0 International License, which permits use, sharing, adaptation, distribution and reproduction in any medium or format, as long as you give appropriate credit to the original author(s) and the source, provide a link to the Creative Commons licence, and indicate if changes were made. The images or other third party material in this article are included in the article's Creative Commons licence, unless indicated otherwise in a credit line to the material. If material is not included in the article's Creative Commons licence and your intended use is not permitted by statutory regulation or exceeds the permitted use, you will need to obtain permission directly from the copyright holder. To view a copy of this licence, visit http://creativecommons.org/licenses/by/4.0/.

\section{Appendix}

See Table 4. 
Table 4 Poverty and fragility scores (dominance and incomparability) by country of origin and length of stay in Italy

\begin{tabular}{|c|c|c|c|c|}
\hline & \multicolumn{2}{|l|}{ Poverty } & \multicolumn{2}{|l|}{ Fragility } \\
\hline & Dominance & Incomparability & Dominance & Incomparability \\
\hline AL_0-2 & 0.2847 & 0.2633 & 0.4461 & 0.411 \\
\hline AL_3-5 & 0.5094 & 0.4155 & 0.464 & 0.4402 \\
\hline AL_6-9 & 0.599 & 0.4009 & 0.4902 & 0.4587 \\
\hline AL_10-14 & 0.6388 & 0.369 & 0.6569 & 0.4267 \\
\hline AL_15+ & 0.6214 & 0.3843 & 0.6614 & 0.4262 \\
\hline CI_0-2 & 0.3584 & 0.332 & 0.6344 & 0.4212 \\
\hline CI_3-5 & 0.542 & 0.4012 & 0.7387 & 0.3862 \\
\hline CI_6-9 & 0.4293 & 0.3857 & 0.7084 & 0.4104 \\
\hline CI_10-14 & 0.6851 & 0.3376 & 0.7218 & 0.4097 \\
\hline CI_15+ & 0.8333 & 0.2146 & 0.7586 & 0.3684 \\
\hline IPSB_0-2 & 0.4239 & 0.3883 & 0.4414 & 0.4282 \\
\hline IPSB_3-5 & 0.4457 & 0.4014 & 0.4879 & 0.4452 \\
\hline IPSB_6-9 & 0.4619 & 0.4029 & 0.453 & 0.4324 \\
\hline IPSB_10-14 & 0.5089 & 0.4218 & 0.5103 & 0.4515 \\
\hline IPSB_15+ & 0.516 & 0.4315 & 0.5355 & 0.4613 \\
\hline LA_0-2 & 0.5426 & 0.4072 & 0.4248 & 0.4057 \\
\hline LA_3-5 & 0.4414 & 0.4121 & 0.4324 & 0.4169 \\
\hline LA_6-9 & 0.5448 & 0.4167 & 0.6389 & 0.4439 \\
\hline LA_10-14 & 0.5775 & 0.4067 & 0.5939 & 0.455 \\
\hline LA_15+ & 0.6133 & 0.3874 & 0.6322 & 0.447 \\
\hline NA_0-2 & 0.3422 & 0.3199 & 0.4158 & 0.4036 \\
\hline NA_3-5 & 0.5127 & 0.4211 & 0.4901 & 0.4641 \\
\hline NA_6-9 & 0.5074 & 0.422 & 0.512 & 0.4584 \\
\hline NA_10-14 & 0.4555 & 0.4083 & 0.47 & 0.4434 \\
\hline NA_15+ & 0.5202 & 0.4267 & 0.5364 & 0.4569 \\
\hline PH_3-5 & 0.5924 & 0.3866 & 0.3578 & 0.3867 \\
\hline PH_6-9 & 0.4426 & 0.3891 & 0.4726 & 0.444 \\
\hline PH_10-14 & 0.8482 & 0.2012 & 0.6957 & 0.3867 \\
\hline PH_15+ & 0.6085 & 0.387 & 0.7548 & 0.3873 \\
\hline RO_0-2 & 0.5251 & 0.4269 & 0.4845 & 0.4493 \\
\hline RO_3-5 & 0.5039 & 0.4289 & 0.5401 & 0.4595 \\
\hline RO_6-9 & 0.4538 & 0.4022 & 0.5627 & 0.4636 \\
\hline RO_10-14 & 0.6392 & 0.3699 & 0.612 & 0.4562 \\
\hline RO_15+ & 0.655 & 0.3621 & 0.6822 & 0.4193 \\
\hline SSA_0-2 & 0.125 & 0.125 & 0.3569 & 0.3531 \\
\hline SSA_3-5 & 0.2649 & 0.2562 & 0.4249 & 0.4113 \\
\hline SSA_6-9 & 0.3888 & 0.3678 & 0.4931 & 0.4523 \\
\hline SSA_10-14 & 0.4673 & 0.4149 & 0.4943 & 0.4541 \\
\hline SSA_15+ & 0.4806 & 0.4218 & 0.5415 & 0.4573 \\
\hline UM_0-2 & 0.5395 & 0.3805 & 0.2743 & 0.2743 \\
\hline UM_3-5 & 0.5067 & 0.3926 & 0.5705 & 0.4606 \\
\hline UM_6-9 & 0.559 & 0.4052 & 0.62 & 0.4579 \\
\hline
\end{tabular}


Table 4 (continued)

\begin{tabular}{llllll}
\hline & \multicolumn{2}{l}{ Poverty } & & \multicolumn{2}{l}{ Fragility } \\
\cline { 2 - 3 } \cline { 5 - 6 } & Dominance & Incomparability & & Dominance & Incomparability \\
\hline UM_10-14 & 0.5631 & 0.4077 & 0.402 & 0.5254 & 0.4655 \\
UM_15+ & 0.5657 & & 0.5353 & 0.4563 \\
\hline
\end{tabular}

\section{References}

Aaberge, R., Andersen, A. S., \& Wennemo, T. (1999). Extent, level and distribution of low income in Norway 1979-1995. In B. Gustafsson \& P. J. Pedersen (Eds.), Poverty and low income in the nordic countries (pp. 131-168). Vermont: Ashgate.

Alkire, S., \& Foster, J. (2011a). Counting and multidimensional poverty measurement. Journal of Public Economics, 95(7-8), 476-487.

Alkire, S., \& Foster, J. (2011b). Understandings and misunderstandings of multidimensional poverty measurement. The Journal of Economic Inequality, 9(2), 289-314.

Arcagni, A. (2017). Parsec: An R package for partial orders in socio-economics. In M. Fattore \& R. Bruggemann (Eds.), Partial order concepts in applied sciences (pp. 275-289). Berlin: Springer.

Arcagni, A., di Belgiojoso, E. B. B., Fattore, M., \& Rimoldi, S. M. (2019). Multidimensional analysis of deprivation and fragility patterns of migrants in Lombardy, using partially ordered sets and selforganizing maps. Social Indicators Research, 141(2), 551-579.

Arndt, C., Distante, R., Hussain, M. A., Østerdal, P. L., Pham, L. H., \& Ibraimo, M. (2012). Ordinal welfare comparisons with multiple discrete indicators: A first order dominance approach and application to child poverty. In WIDER working paper, 2012/36, ISBN 978-92-9230-499-7.

Baio, G., Blangiardo, G. C., \& Blangiardo, M. (2011). Centre sampling technique in foreign migration surveys: Amethodological note. Journal of Official Statistics, 27(3), 451-465.

Bárcena-Martìn, E., \& Pérez-Moreno, S. (2016). Immigrant-native gap in poverty: A cross-national European perspective. Review of Economics of the Household. https://doi.org/10.1007/s1115 0-015-9321-X.

Berti, F., D’Agostino, A., Lemmi, A., \& Neri, A. (2014). Poverty and deprivation of migrants versus natives in Italy. International Journal of Social Economics, 41(8), 630-649.

Blangiardo, G. C. (2008). L'immigrazione straniera in Lombardia. La settima indagine regionale. Rapporto 2017. Milano: ISMU-ORIM.

Busetta, A. (2016). Foreigners in Italy: Economic living conditions and unmet medical needs. Genus, $71,2-3$.

Constant, A., Roberts, R., \& Zimmermann, K. (2009). Ethnic identity and immigrant homeownership. Urban Studies, 46(9), 1879-1898.

Curatolo, S., \& Wolleb, G. (2010). Income vulnerability in Europe. In C. Ranci (Ed.), Social vulnerability in Europe. The new configuration of social risk. Chipenham: Palgrave Macmillan.

Davey, B. A., \& Priestley, B. H. (2002). Introduction to lattices and order. Cambridge: CUP.

Davidov, E., \& Weick, S. (2011). Transition to homeownership among immigrant groups and natives in West Germany, 1984-2008. Journal of Immigrant \& Refugee Studies, 9(4), 393-415.

de Bustillo, R. M., \& Anton, J. I. (2011). From rags to riches? Immigration and poverty in Spain. Population Research and Policy Review, 30, 661-676.

di Belgiojoso, E. B., Chelli, F. M., \& Paterno, A. (2009). Povertá e standard di vita della popolazione straniera in Lombardia [Poverty and living standard of foreign population in Lombardy Region]. Rivista Italiana di Economia, Demografia e Statistica, LXIII, 3(4), 23-30.

di Belgiojoso, E. B., \& Rimoldi, S. (2005). Povertá e immigrazione straniera: Resoconto dellesperienza di unindagine pilota nella realtá lombarda. In G. Rovati (Ed.), Le dimensioni della povertá. Strumenti di misura e politiche. Roma: Carocci.

Diana, P., \& Strozza, S. (2014). Strategie abitative degli immigrati nel casertano: la costruzione di una tipologia. In P. Donadio, G. Gabrielli, \& M. Massari (Eds.), Uno come te. Europei e nuovi europei nei percorsi di integrazione (pp. 262-279). Milano: Franco Angeli.

Fattore, M. (2016). Partially ordered sets and the measurement of multidimensional ordinal deprivation. Social Indicators Research, 128(2), 835-858. 
Fattore, M., \& Arcagni, A. (2018). A reduced posetic approach to the measurement of multidimensional ordinal deprivation. Social Indicators Research. https://doi.org/10.1007/s11205-016-1501-4.

Fattore, M., \& Arcagni, A. (2019). F-FOD: Fuzzy first-order dominance analysis and populations ranking over ordinal multi-indicator systems. Social Indicators Research, 144(1), 1-29.

Fellini, I., \& Migliavacca, M. (2010). Unstable employment in Western Europe: Exploring the individual and household dimensions. In C. Ranci (Ed.), Social vulnerability in Europe. The new configuration of social risk. Chippenham: Palgrave Macmillan.

Fernades, A., \& Pereira, M. J. (2009). Health and migration in the European Union: Better health for all in an inclusive society. London: Pro-book, Publishing Limited.

Galloway, T. A., \& Aaberge, R. (2005). Assimilation effects on poverty among migrants in Norway. Journal of Population Economics, 18(4), 691-718.

Giannoni, M. (2010). Migrants inequalities in unmet needs for access to health care in Italy. In Paper presented at the 15th Aies conference, Moncalieri, Italy.

Gobillon, L., \& Solignac, M. (2015). Homeownership of migrants in France: Selection effects related to international migration flows, Discussion Paper 9517. Institute for the Study of Labor (IZA).

Hansen, J., \& Lofstrom, M. (2003). Immigrant assimilation and welfare participation do migrants assimilate into or out of welfare? Journal of Human Resources, 38(1), 74-98.

Hansen, J., \& Wahlberg, R. (2009). Poverty and its persistence: A comparison of natives and migrants in Sweden. Review of the Economics of the Household, 7, 105-132.

Istat. (2018). La povertà in Italia. https://www.istat.it/it/archivio/217650.

Istat. (2019). Demographic statistics Istat. http://www.demo.istat.it/str2018/index.html.

Kazemipur, A., \& Halli, S. S. (2001). Migrants and'New Poverty': The case of Canada. International Migration Review, 35(4), 1129-1156.

Koolman, X. (2007). Unmet need for health care in Europe, in EUROSTAT, Comparative EU statistics on income and living conditions: Issues and challenges. In Proceedings of the EU-SILC conference (pp. 181-191).

Koutsampelas, C. (2015). Blind spots of traditional poverty measurement: The case of migrants. Migration Letters, 12(2), 103-112.

Lelkes, O. (2007). Poverty among migrants in Europe. Policy Brief April 2007. Vienna: European Centre for Social Welfare Policy and Research.

Lemmi, A., Berti, F., Betti, G., D’Agostino, A., Gagliardi, F., Gambacorta, R., et al. (2013). Povertà e deprivazione. In C. Saraceno, N. Sartor, \& G. Sciortino (Eds.), Stranieri e disuguali (pp. 149-174). Bologna: Il Mulino.

Lie, B. (2002). Immigration and immigrants (pp. 1-113). Statistical Analyses 54, Statistics Norway, Norway.

Myers, D., \& Lee, S. W. (1998). Immigrant trajectories into home ownership: A temporal analysis of residential assimilation. International Migration Review, 32(3), 593-625.

Neggers, J., \& Kim, S. H. (1998). Basic posets. Singapore: World Scientific.

Obućina, O. (2014). Paths into and out of poverty among migrants in Sweeden. Acta Sociologica, 57(1), $5-23$.

Pastor, M. (2014). Stepping stone or sink hole? Migrants, poverty, and the future of Metropolitan America. In Conference paper, innovating to end urban poverty conference, March 27-28, University of Southern California, Los Angeles.

Pemberton, S., Phillimore, J., \& Robinson, D. (2014). Causes and experiences of poverty among economic migrants in the UK. In IRiS working paper series, 4, University of Birmingham.

Pradhan, P., Costa, L., Rybski, D., Lucht, W., \& Kropp, J. P. (2017). A systematic study of sustainable development goal (SDG) interactions. Earth's Future, 5, 1169-1179. https://doi.org/10.1002/2017E F000632.

R Core Team. (2019). R: A language and environment for statistical computing. R Foundation for Statistical Computing, Vienna, Austria. https://www.R-project.org/.

Rimoldi, S. M. L., \& di Belgiojoso, E. B. (2016). Poor migrants! Evidence from the Italian Case. Athens Journal of Social Sciences, 3(2), 99-112.

Robinson, R., Reeve, K., \& Casey, R. (2007). The housing pathways to migrants. York: Joseph Rowntree Foundation.

Sanguilinda, I. S., di Belgiojoso, E. B., González, Ferrer A., Rimoldi, S. M. L., \& Blangiardo, G. C. (2017). Surveying immigrants in Southern Europe: Spanish and Italian strategies in comparative perspective. Comparative Migration Studies, 5, 17. https://doi.org/10.1186/s40878-017-0060-4.

Schröder, B. S. (2003). Ordered sets (pp. 29-30). Berlin: Springer. 
Sullivan, D. H., \& Ziegert, A. L. (2008). Hispanic immigrant poverty: Does ethnic origin matter? Population Research and Policy Review, 27(6), 667.

Publisher's Note Springer Nature remains neutral with regard to jurisdictional claims in published maps and institutional affiliations. 